\title{
Entre reflexões e fazeres: a construção do saber histórico escolar a partir do uso de reflexórios
}

Between reflections and actions: the construction of school historical knowledge from the use of reflective writing

Entre reflexiones y acciones: la construcción del conocimiento histórico escolar a partir del uso de la escritura reflexiva

Diego Firmino Chacon

Orcid: https://orcid.org/0000-0002-7054-683X

Secretaria Municipal de Educação de Arez e Secretaria da Educação e da Cultura do Estado do Rio Grande do Norte, Arez, Brasil, diegofchacon@hotmail.com

Francisco Firmino Sales Neto

Orcid: https://orcid.org/0000-0001-9647-4638

Universidade Federal de Campina Grande, Cajazeiras, Brasil, nassausiegen@yahoo.com.br

Dinara Soares Chacon Sales

Orcid: https://orcid.org/0000-0003-4027-1414

Universidade de Trás-os-Montes e Alto Douro, Vila Real, Portugal, dinarachacon@yahoo.com.br

Received on 29/11/2020 - Approved on 02/12/2020

\section{Resumo}

Este trabalho analisa o uso de "reflexórios" como estratégia para ressignificar as aprendizagens nas aulas de História. As experiências aqui analisadas surgiram na atuação junto ao componente curricular História para o Ensino Médio, na Escola Estadual Jacumaúma, em Arez, Rio Grande do Norte. Elas se basearam na produção de textos reflexivos pelos estudantes sobre suas próprias vivências e aprendizagens em sala de aula. $\mathrm{O}$ desenvolvimento dessa prática de observar, refletir e sistematizar - por meio da escrita - os múltiplos movimentos e saberes no cotidiano das aulas contribuiu para que os educandos fossem percebendo as contribuições do saber histórico para as suas vidas e para a sociedade. No diálogo com teóricos como Geertz (2012; 2014), Rusen (2010), Certeau (2014), Ricoeur 
(2011; 2018) e Elias (1998) foram percebidos saberes históricos nos enunciados construídos pelos estudantes em seus reflexórios, marcados por elaborações e reelaborações características das dinâmicas mutáveis da cultura escolar.

Palavras-chaves: Saber histórico escolar; Ensino Médio; Reflexório; Aprendizagem.

\begin{abstract}
This paper analyzes the use of reflective writing (a Portuguese neologism reflexório) as a strategy to reframe the learning in History classes. The experiences analyzed here arose in working with the curriculum component History for High School, at Jacumaúma State School, in Arez, Rio Grande do Norte. They were based on the production of reflective texts by students about their own experiences and learning in the classroom. The development of this practice of observing, reflecting and systematizing - through writing - the multiple movements and knowledge in the daily routine of the classes contributed to the students being aware of the contributions of historical knowledge to their lives and to society. In the dialogue with theorists such as Geertz (2012; 2014), Rusen (2010), Certeau (2014), Ricoeur (2011; 2018) and Elias (1998), historical knowledge was perceived in the statements constructed by the students in their reflections, marked by elaborations and characteristic reelaborations of the changing dynamics of school culture.
\end{abstract}

Keywords: School historical knowledge; High school; Reflective writing; Learning.

\title{
Resumen
}

Este trabajo analiza el uso de la escritura reflexiva (el neologismo portugués reflexório) como estrategia para replantear el aprendizaje en las clases de Historia. Las experiencias aquí analizadas surgieron en el trabajo con el componente curricular Historia para el Bachillerato, en la Escuela Estatal Jacumauma, en Arez, Rio Grande do Norte. Se basaron en la producción de textos reflexivos por parte de los estudiantes sobre sus propias experiencias y aprendizajes en el aula. El desarrollo de esta práctica de observar, reflexionar y sistematizar - a través de la escritura - los múltiples movimientos y saberes en el día a día de las clases contribuyó a que los estudiantes tomaran conciencia de los aportes del conocimiento histórico a su vida y a la sociedad. En el diálogo con teóricos como Geertz (2012; 2014), Rusen (2010), Certeau (2014), Ricoeur (2011; 2018) y Elias (1998), el conocimiento histórico se percibió en los enunciados construidos por los estudiantes en sus reflexiones, marcados por elaboraciones y reelaboraciones características de la dinámica cambiante de la cultura escolar.

Palabras clave: Conocimiento histórico escolar; Bachillerato; Escritura reflexiva; Aprendizaje.

\section{Palavras iniciais}

Neste artigo analisamos a utilização de "reflexórios" como estratégia para refletirmos, compreendermos e, assim, ressignificarmos as aprendizagens nas aulas de História. 
A princípio, cumpre destacarmos que a palavra "Reflexório" é um neologismo utilizado como referência a um texto em que são refletidas e relatadas as aprendizagens dos alunos, durante as experiências em sala de aula (PERISSÉ, 2004).

A apropriação dessa estratégia de ensino nas aulas de História, particularmente no Ensino Médio, decorre de inquietações surgidas no fazer docente. Esses questionamentos levavam em consideração a necessidade de o ensino de História escolar suscitar, nos discentes, uma postura de sujeitos mais ativos na produção dos conhecimentos históricos elaborados no cotidiano da sala de aula.

Tais inquietações estão em sintonia com debates desenvolvidos entre profissionais da área de História, desde meados da década de 1980, acerca das novas concepções que deveriam nortear os conteúdos e metodologias do ensino escolar dessa disciplina, desvinculando-a de uma perspectiva tradicional. Nessa postura, aqui chamada de tradicional, o professor acabava representando o produtor e divulgador do verdadeiro saber histórico e os alunos tornavam-se, no espaço escolar, potenciais memorizadores e reprodutores daquilo que foi ensinado nas aulas (Schmidt; Cainelli, 2009).

Também ligado a esse protagonismo dos alunos, apropriar-nos dos usos dos reflexórios no ensino de História tinha a preocupação em tornarmos os espaços das aulas em momentos nos quais os discentes pudessem expor suas subjetividades no processo de elaboração de sua escrita e de leitura de seus textos. Dessa maneira, eles mesmos poderiam realizar um processo de aproximação e de ressignificação de suas experiências pessoais e sociais, em diálogo com os conteúdos propostos na disciplina. De acordo com Rusen (2010, 2011), o diálogo com a subjetividade no processo de ensinar História propicia o desenvolvimento de uma das funções primordiais do saber histórico que é orientar as questões da vida prática.

A terceira dimensão do uso dos reflexórios está relacionada a necessidade de nos distanciarmos das compreensões dominantes nos contextos escolares sobre a avaliação da aprendizagem como algo limitado a uma dimensão somativa. $\mathrm{Na}$ disciplina de História, herdou-se uma postura de valorizar/enfatizar mecanismos de avaliação de cunho bastante próximo aos resultados de memorização de conteúdos conceituais em momentos pontuais do processo de ensino-aprendizagem. Esse modo de perceber o processo avaliativo perpassa e permanece em todos os níveis de ensino brasileiro e acaba obliterando os múltiplos potenciais redirecionadores dos procedimentos de ensinar e aprender contidos na avaliação escolar (Hoffmann, 2014).

A experiência com o uso dos reflexórios no ensino de História ocorreu na Escola Estadual Jacumaúma, no município de Arez, no Estado do Rio Grande do Norte. As atividades iniciaram-se com as primeiras, segundas e terceira séries do Ensino Médio no ano de 2017 e permaneceram sendo realizadas até o ano de 2019, com as devidas adequações.

Portanto, o objetivo deste trabalho reside em compreendermos o uso dos "Reflexórios" como estratégia para refletirmos e ressignificarmos as aprendizagens nas aulas de História. No intuito de alcançarmos essa finalidade, o artigo ficou estruturado da seguinte maneira: primeiramente, explicamos os fundamentos conceituais e metodológicos que deram origem aos reflexórios e as transformações feitas em suas estruturas e compreensões para assim adequá-los aos processos de ensino-aprendizagem na disciplina de História. Depois disso, relatamos os 
passos dados por alunos e pelo professor desde a proposição das atividades com os reflexórios até a construção, leitura, reconstrução e entrega final dos textos. Por fim, analisamos as produções dos discentes da terceira série do Ensino Médio, levando em consideração uma das dimensões apresentadas para a produção dos reflexórios: as contribuições do saber histórico para a vida.

\section{Reflexório: o que é isso?}

O primeiro contato com o termo que nomeia a estratégia aqui utilizada Reflexório - foi por meio de um texto de Perissé (2004). Nesse trabalho, ele descreve que a utilização de reflexórios surgiu como uma das estratégias do Projeto The Global School, realizado com crianças do Centro de Educação Fundamental da Escola de Educação Internacional da Bahia.

Segundo Perissé (2004), os reflexórios eram textos elaborados por alunos, entre 6 e 10 anos, cuja função era refletir e relatar as aprendizagens das crianças. Semanalmente, as produções eram enviadas aos professores usando as Tecnologias da Informação e Comunicação (TIC). O foco, assim, não se direcionava a enumerar atividades, mas refletir sobre elas. Nesse processo de produção textual refletir significava, entre outros aspectos, pensar sobre os significados, os sentimentos e as conclusões que procediam daqueles processos de aprendizagem.

No desenrolar das discussões, Perissé (2004) compreendeu que o uso dos reflexórios oportunizava a familiarização dos discentes com uma escrita e leitura reflexiva e criativa, visto que essa tática fazia com que eles escrevessem e lessem para comunicarem sistematicamente aquelas informações observadas. Nesse caso, ao conceder regularidade ao ato de ler e escrever no espaço escolar, essas atividades acabaram também se distanciando de práticas artificiais e mecânicas no trato da produção e reprodução textuais no contexto das aulas.

É importante pensarmos que, nesse caso, a preocupação com a linguagem estava na chave da proposição de metodologias para as ações desenvolvidas no espaço escolar. Isso porque, enquanto linguagem educacional, o reflexório é também um gênero textual utilizado para dinamizar as aulas e estimular procedimentos reflexivos entre professores e alunos durante o processo de aprendizagem. E isso não remete apenas às aulas do componente curricular Língua Portuguesa, mas também às demais humanidades, como a História, estabelecendo metodologias ativas e colaborando no protagonismo discente e, de maneira interdisciplinar, na constituição de saberes históricos escolares.

Nesse diálogo interdisciplinar, considerando sua dimensão textual e histórica, a noção de gênero textual utilizada para uma melhor definição e uso da estratégia de trabalho com os reflexórios se baseia nas proposições de Marcuschi (2010). Partindo da percepção que as tecnologias hodiernas são pródigas na constituição de gêneros textuais, Marcuschi estabelece uma definição dinâmica para o termo, enquanto eventos textuais dinamizadores da ação criativa humana pela linguagem. Ao que afirmou:

[...] os gêneros textuais são fenômenos históricos, profundamente vinculados à vida cultural e social. Fruto de trabalho coletivo, os gêneros contribuem para ordenar e estabilizar as atividades comunicativas do dia a dia. São entidades 
sociodiscursivas e formas de ação incontornáveis em qualquer situação comunicativa (Marcuschi, 2010, p. 19).

Nesse sentido, para além do neologismo, o uso de reflexórios é uma estratégia de trabalho com gêneros textuais - entendidos enquanto linguagem educacional a serviço do pensamento histórico - que estimulam a capacidade reflexiva e comunicativa dos alunos. Com o propósito de materializar essas atividades com os reflexórios nas aulas de História do Ensino Médio e torná-los significativos nos processos de ensinar e aprender na disciplina, criou-se uma estrutura que deveria orientar os alunos na construção de seus textos.

O cenário escolar, o nível de ensino e a especificidade do saber histórico praticado em aula fizeram com que a definição de reflexório conservasse alguns fundamentos da proposta de Perissé (2004), mas também que se distanciasse em outros. Isso ocorreu na medida em que a construção de uma estrutura norteadora da escrita possibilitou que o reflexório ganhasse novas características e usos que pudessem contribuir com o desenvolvimento do pensamento histórico pelos alunos.

Assim, os reflexórios se tornaram textos que relatariam e refletiriam os acontecimentos semanais das aulas de História, no Ensino Médio, apresentando sentimentos, inquietações e interpretações acerca daqueles momentos de ensinoaprendizagem. Ao serem escritos, eles poderiam levar em consideração cinco dimensões: a descrição, a análise, a interpretação, a comparação e as contribuições para a vida.

Ao conceituarmos os reflexórios como um texto cujas características são relatar e refletir sobre as aulas de História, tal noção apóia-se na compreensão de que existe uma cultura escolar. E esta é percebida como textos que podem ser lidos e interpretados. Pois, os múltiplos modos de fazer, organizar e, até mesmo, de não fazer no cenário escolar e da sala de aula possuem significados elaborados pelos próprios sujeitos que constituem aquele espaço (Geertz, 2012).

Em sintonia com as afirmações anteriores as aulas de História, com seus alunos, professores, métodos, movimentos, falas, silêncios e posturas diversas, colocam-se como lugares onde se encontram miríades de sentidos e significados a serem descritos e interpretados pelos próprios discentes nos seus reflexórios. Assim, os alunos se deslocariam de uma postura de meros expectadores e absorvedores de conteúdos pré-estabelecidos para uma postura de sujeitos ativos na construção de suas próprias narrativas sobre os processos de ensinar e aprender em História.

No tocante à organização da estrutura do reflexório, as três primeiras dimensões a serem consideradas foram a descrição, a análise e a interpretação. Quando pensamos em criá-las, elas tinham como objetivo que os alunos pudessem compreender as maneiras possíveis que os ajudariam a ir além de uma descrição superficial, ou seja, apenas de relatar e enumerar fatos isolados em sala de aula.

Para essa empreitada, as três dimensões citadas acima foram entendidas a partir das discussões empreendidas por Geertz (2012). Para ele, tais processos estão unidos e constituem a "descrição densa". Aqui, relatar e refletir permanecem casados para que as práticas, interações e os discursos possam ser descritos em profundidade. O mais banal, as relações mais comuns em sala de aula podem ser enriquecidas e ganham singularidades em sua ligação a uma teia de significados elaborados socialmente. Essa perspectiva nos é explicada pelo próprio estudioso: 
Compreender a cultura de um povo expõe a sua normalidade sem reduzir sua particularidade. (Quanto mais eu tento seguir o que fazem os marroquinos, mais lógico e singular eles me parecem.) Isso os torna acessíveis colocá-los no quadro de suas próprias banalidades dissolve sua opacidade (Geertz, 2010, p. 10).

Essa ligação entre descrever, analisar e interpretar presente na descrição densa, cuja preocupação é fazer a conexão entre os significados, aproxima-se da perspectiva de interpretação de Ricoeur (2018). Na compreensão proposta pelo filósofo francês, a interpretação acontece no processo em que o leitor é expandido em sua capacidade de autoprojeção, quando ele recebe do texto lido um novo modo de ser, ou novas formas de vida próprias de um determinado contexto: "É o texto, com o seu poder universal de desvelamento de um mundo, que fornece um si mesmo ao ego" (Ricoeur, 2018, p. 132).

Ao pensarmos esses três pontos do reflexório a partir das ideias que foram expostas, abrem-se espaços para que o universo criativo e simbólico dos alunos seja posto em prática, na medida em que suas leituras e, por consequência, escritas dos conteúdos e das dinâmicas das aulas de História seriam potencializadas, perpassadas e emaranhadas pelas suas experiências próprias de vivência no mundo. Assim, objetividade e subjetividade dialogariam no percurso de interpretação e produção textual dos reflexórios.

Nas quarta e quinta dimensões, dedicadas à comparação e às contribuições para a vida, buscamos desenvolver nos alunos as noções de espaço e tempo. Esses dois aspectos são inerentes ao saber histórico, como explica Chartier (2010, p. 65): "[...] a especificidade da história, dentro das ciências humanas e sociais, é sua capacidade de distinguir e articular os diferentes tempos que se acham superpostos em cada momento histórico." A intenção era contribuir para que os discentes percebessem que o tempo trabalhado pela História não se limitava apenas ao tipo cronológico. Junto a isso, também estava o esforço de tomarem consciência que, nos diferentes espaços, ao longo do tempo, as sociedades assumem múltiplos modos de viver e se organizar. Pois como expressa Bittencourt:

[...] as apreensões do espaço em suas relações mais complexas tornam-se fundamentais para o conhecimento histórico e não se limitam a apenas localizar os espaços pelas representações cartográficas. Estas são, sem dúvidas, fundamentais, mas precisam estar associadas as apreensões dos espaços vividos e percebidos pelos diferentes grupos sociais (Bittencourt, 2004, p. 210).

Outro elemento motivador aqui foi proporcionar aos alunos a compreensão de que as experiências passadas, estudadas na disciplina de História, podem servir como elementos geradores de reflexões para interpretar suas próprias posturas e tomadas de decisões. E, ainda, para compreender as posturas e tomadas de decisões de determinados grupos sociais. De acordo com Schmidt e Cainelli (2009), esse entendimento é importante, pois compreende o esforço de produzir um diálogo entre as realidades do presente e do passado, que se tornariam úteis na formação de um futuro socialmente responsável. Sem falar que há dois aspectos potencializadores nessa visão: um direcionado à construção de uma identidade 
pessoal; e outro à função da História como orientadora de uma posição crítica diante da vida, ou seja, o exercício do pensamento histórico.

Para ficar mais compreensível aos alunos a maneira de eles elaborarem as quarta e quinta parte do reflexório, orientamos que, na comparação, tentassem apresentar no texto as diferenças percebidas por eles entre as sociedades no estudo dos diferentes conteúdos desenvolvidos em sala de aula. Percebam aí que a comparação gira em torno da noção de diferença entre duas sociedades - em temporalidades distintas, mas no próprio passado.

Ao pensarmos dessa maneira, buscamos desenvolver nos discentes a capacidade de se interessassem por outras sociedades, sensibilizando-os para as diferenças e evitando, com isso, os possíveis anacronismos. Esse pressuposto metodológico é um instrumento de aprender a contextualizar dadas situações da História e evitar correlações duvidosas (Schimidt; Cainelli, 2009).

Relativamente, à parte das contribuições para a vida, tentamos instigar os alunos a apresentarem as possíveis mudanças ou continuidades entre as experiências passadas e aquelas experienciadas por eles e pela sociedade que os envolve atualmente. Aqui os estimulamos a exporem seus pontos de vista sobre os motivos de tais transformações ou permanências e em que elas influenciariam a realidade hodierna. Os alunos, ao procurarem organizar as narrativas levando em conta esses pontos, abrem-se a um aprendizado em que eles mesmos se dedicam a encontrar sentidos nas experiências temporais por meio dos estudos da História (Rusen, 2011)

Durante as discussões empreendidas até aqui, houve um esforço em explicitar os fundamentos conceituais que nortearam os primeiros contatos com a estratégia dos reflexórios. E como, a partir daí, surgiram o interesse de colocá-la em prática nas aulas do Ensino Médio, dando-Ihes uma identidade mais em sintonia com as novas realidades desse nível de ensino, do contexto escolar peculiar e das especificidades de aprendizagem no campo de saber histórico escolar.

\section{Artes de fazer e refazer reflexórios}

Neste momento, serão descritos os caminhos percorridos por alunos e professor, durante as aulas de História, para a construção dos reflexórios. As atividades iniciaram-se no ano letivo de 2017, na Escola Estadual Jacumaúma. Elas aconteceram em cinco turmas do Ensino Médio, no turno vespertino, sendo duas primeiras séries; duas segundas séries; e uma terceira série.

Antes de detalhamos esse percurso, torna-se necessário esclarecermos que o trabalho aqui realizado foi fundamentado na concepção de que o processo de ensino e investigação é indissociável um do outro. Esse prisma se faz possível porque, nas abordagens mais recentes da didática, comunga-se do entendimento de que a sala de aula não é apenas lugar de reprodução de conhecimentos. Ao contrário, ela se revela como espaço dinâmico e em movimento. Lugar que oferece possibilidades aos professores de aprofundarem seus questionamentos e de buscarem novos sentidos e significados para suas próprias práticas e para seus aperfeiçoamentos profissionais. Foi em afinamento com tais visões que a produção dos reflexórios tornou-se um processo baseado em reflexões, sistematizações, mudanças de entendimentos e posturas tanto por parte do professor, quanto dos alunos. Como consequência dessa compreensão: 
[...] a atuação do professor caracteriza-se como um trabalho de pesquisa-ação, em que reflexão e ação, teoria e prática se articulam para reconstruir e aperfeiçoar as atividades curriculares. Neste contexto, o professor torna-se um produtor de conhecimento prático sobre o ensino (Garrido, 2001, p. 138).

No início do ano letivo, propomos aos alunos uma maneira distinta de desenvolver as atividades avaliativas. Também thes foi dito que estas se distanciariam dos modelos costumeiramente praticados por eles, que eram pautados em uma lógica pontual de elaboração de exercícios centrados na memorização. E que haveria, a partir de então, o enveredamento pelos caminhos da produção de reflexórios, que lhes exigiriam um maior esforço na elaboração de textos em torno das aulas de História.

Para proporcionar que o conceito de reflexório e sua estrutura fossem explicados de uma forma a ser compreensível pelos alunos do Ensino Médio da escola pública foi realizada uma espécie de mediação didática das definições e finalidades de cada dimensão do reflexório. Essa estratégia ficou organizada em tópicos e exemplificações. Sobre essa prática, Monteiro (2007) concluiu que as exemplificações são usadas no ensino de História com o intuito de articular diversos elementos do contexto para a compreensão dos conceitos.

A apresentação desses conceitos e da estrutura do reflexório foi realizada em todas as turmas, durante as primeiras aulas do ano letivo. Isso ocorreu pela distribuição de roteiros para que cada um dos alunos pudesse ler e, logo, se familiarizar com a proposta de uma escrita reflexiva. Adiante, observamos como ficou o roteiro citado:

Quadro 1: Orientações Para a Elaboração dos Reflexórios

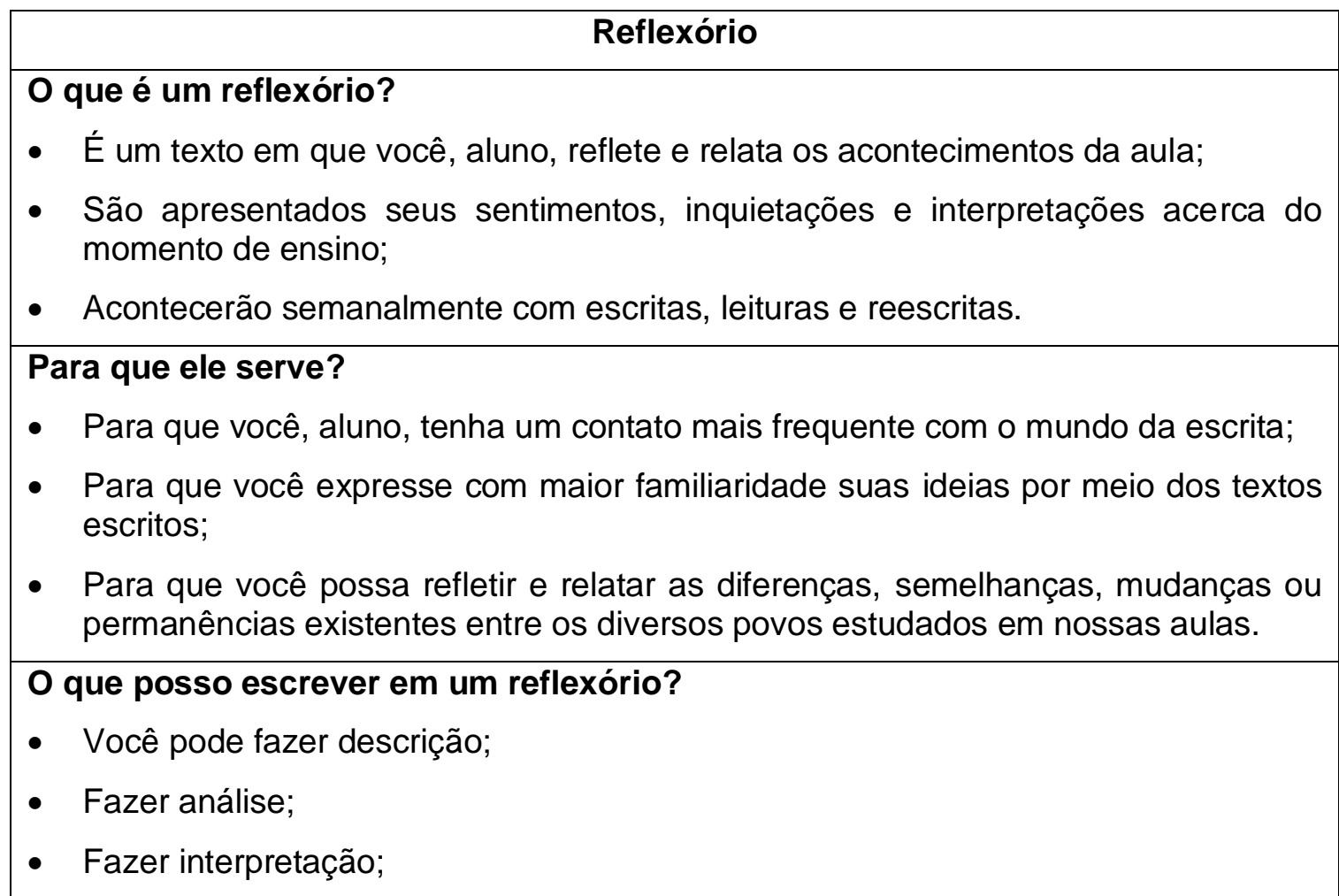


- Fazer comparação;

- E trazer contribuições para a vida.

Mas, professor, o que devo descrever, analisar e interpretar?

- Não há como separar descrição, análise e interpretação;

- Escrever o que acontece exige que você, aluno, acabe colocando também suas ideias, pensamentos, inquietações, impressões e opiniões acerca do que foi relatado;

- Tudo isso dito acima une o descrever, o analisar e o interpretar na hora de escrever. Exemplificando:

No meu pensamento, a sala foi organizada assim por causa disso...; Esse conteúdo, eu vi outra vez em tal série e me lembro disso e aquilo sobre ele...; Essas atitudes dos alunos ou professor me chamaram a atenção por que tem relação com o seguinte fato que aconteceu de outra vez em tal lugar...; Eu me lembro de que essa parte da aula tem a ver com que passou no filme tal e, no filme, eles falaram sobre esse ponto e na aula sobre esses outros.

\section{E como comparar? E trazer as contribuições para a vida?}

- Você, aluno, pode apresentar diferenças entre dois povos, estudados nos conteúdos;

- Você pode buscar relações das atividades e conhecimentos desenvolvidos nas aulas para sua vida e para a daquelas pessoas que estão vivendo na sociedade hoje.

\section{Exemplificando:}

Entendi que naquele conteúdo passado a sociedade era organizada dessa maneira e que nesse conteúdo essa sociedade é organizada de maneira diferente por causa desses pontos...; Percebi que na Idade Média as mulheres só podiam usar vestidos longos e hoje elas podem usar vários tipos de roupas diferentes e essas mudanças ocorreram por diversos fatores... que trouxeram transformações também nestes pontos de nossas vidas hoje...

Fonte: Elaboração dos autores.

Ao longo do diálogo com as turmas, chegamos a algumas conclusões acerca das dinâmicas para se trabalhar com os reflexórios. Primeiro, os alunos dedicariam um espaço no caderno somente para a escrita e reescrita desses textos. Segundo, em cada bimestre letivo, eles buscariam escrever cinco reflexórios. Terceiro, no decorrer de cada bimestre, também escolheriam um desses textos escritos para serem lidos, apreciados e debatidos em sala de aula. Quarto, no final do ano letivo, selecionariam dois reflexórios, considerados por eles mesmos como os mais significativos, para entregarem ao docente.

Apesar de todas as incertezas que perpassam um ano letivo na escola pública de nível Médio brasileira, conseguiu-se manter a rotina daquilo que se concordou em fazer. O resultado quantitativo da escrita dos reflexórios foi 0 seguinte: 
Quadro 2: Dados Numéricos Sobre os Reflexórios

\begin{tabular}{|c|c|c|c|}
\hline Séries & Turmas & № de Alunos & № de Reflexórios \\
\hline $1^{\text {a }}$ & A e B & 82 & 287 \\
\hline $2^{\text {a }}$ & A e B & 102 & 377 \\
\hline $3^{\text {a }}$ & A & 35 & 140 \\
\hline
\end{tabular}

Fonte: Elaboração dos autores.

A construção dos reflexórios pelos alunos, nos bimestres, ficou planejada em duas etapas. Em uma semana, eles escreveriam suas observações das aulas para construção dos seus textos. E na semana posterior, dedicar-se-iam à leitura dos reflexórios, que acontecia no primeiro horário da aula. A partilha dos escritos ocorria com aqueles discentes que se ofereciam para ler junto à turma. Em média, entre três e cinco alunos liam seus textos.

Esse espaço de leitura partilhada servia para motivar a colaboração entre os colegas, em relação a possíveis reconstruções mútuas de seus textos. Com isso, almejávamos tornar a sala de aula em um espaço formador para esses alunos, em que eles aprendessem a pensar, elaborar e expressar melhor suas ideias e a ressignificar seus conhecimentos (Garrido, 2001). Também, para que eles mesmos expusessem suas impressões e inquietações sobre o processo de ensinoaprendizagem, contribuindo para a reflexão do próprio docente sobre a sua prática cotidiana no ensino de História.

Ao lado de outras atividades ao longo do bimestre, a escrita e a leitura dos reflexórios foram consideradas como parte dos requisitos para a obtenção de notas, exigidas pelo sistema de ensino. Ao término do quarto bimestre, os alunos foram orientados a relerem seus textos em casa; a selecionarem dois textos que considerassem mais significativos ao longo de suas produções anuais; a digitarem aqueles escolhidos e que, além de seus dados estudantis, pusessem um apelido e entregassem os textos ao professor para que este pudesse arquivá-los na biblioteca da escola. Assim, poderiam servir de exemplo e serem consultados, nos anos à frente, por outros discentes; como também serem usados enquanto fonte de pesquisa para outros docentes. Mesmo porque as experiências vivenciadas na sala de aula e na escola podem contribuir para a profissionalização do professor. Isso acontece quando ele compreende as práticas que acontecem nesses espaços como objeto de reflexão, com o objetivo de construir e reconstruir modos de fazer que contribuam para a melhoria do ensinar e do aprender (Garrido, 2001).

$O$ resultado quantitativo foi que, ao final do ano, os alunos das primeiras séries devolveram cento e sessenta e quatro; os das segundas séries, duzentos e quatro; e os das terceiras séries, setenta reflexórios.

Como se pode ler, aqui foram apresentadas as fases que constituíram a proposta de uso dos reflexórios: desde a apresentação da proposta de elaboração desse texto de perfil reflexivo até a entrega ao professor dos textos selecionados, passando pelos momentos da escrita, reescrita e partilha dos textos, em sala de aula, pelos alunos. Além disso, apresentamos os dados quantitativos anuais acerca da participação dos discentes na construção dos reflexórios. 


\title{
Saberes, experiências e reflexões: um saber histórico escolar praticado
}

Nessa parte, buscamos interpretar as produções dos discentes da terceira série do Ensino Médio, levando em consideração uma das dimensões apresentadas para a produção dos reflexórios: as contribuições do saber histórico para a vida. A escolha dessa temática específica para analisar as fontes, e a preferência pelas produções de uma única série, foi devido à própria natureza do artigo científico, que exige do pesquisador a opção por questões mais específicas, em meio a tantas outras possíveis, para serem apresentadas diante do amplo desenvolvimento da investigação.

As narrativas dos alunos se constituem como espaços onde se podem criar resistências à propagação e à imposição de um saber padronizado e uníssono sobre os fatos históricos em sala de aula. Assim, os posicionamentos políticos dos discentes são expressos nos relatos sobre os acontecimentos históricos. No entendimento da estudante Bia, o processo de reabertura na Ditadura Civil-militar teve recuo e ela aponta como causa disso a anistia indistinta para as duas partes, perseguidos e perseguidores. Já o aluno Zerodois identificou a permanência da troca de favores na política brasileira, desde a República Oligárquica até hoje, como fator de colaboração para o agravamento da situação de governança no país. 0 educando Dido tentou justificar a atitude autoritária no período Vargas por meio do argumento de que o congresso brasileiro é um lugar historicamente caracterizado por práticas ilegais. O texto acabou se tornando lugar de outros enunciados, os quais são emaranhados pelos posicionamentos políticos dos estudantes, como se observa a seguir:

\begin{abstract}
As características dos momentos finais do regime militar, o período de reabertura política do Brasil, considerada por ser uma reabertura lenta, segura e com retrocessos, porque foi aprovada a anistia para perseguidores e perseguidos do regime militar no ano de 1979 (Bia, 2017).

Normalmente, já de rotina de várias semanas, a sala de módulo oval, foi imposto uma discussão sobre o governo oligárquico, debatemos e definimos que até hoje ainda existe no século XXI, as trocas de favores: Você faz isso e te dou isso. Exemplo: todos juntos pra um governo pior (Zerodois, 2017).

Em um dos momentos da aula foi dito pelo nosso grupo que o Brasil só presta quando se fecha o congresso. Vargas entendeu muito bem isso. Se relacionarmos isso com os dias atuais, vemos que toda sujeira do país está realmente localizada no congresso (Dido, 2017).
\end{abstract}

O interessante compreender aqui é que a narrativa desenvolvida pelo professor e pelo manual didático não é reproduzida nesses reflexórios de modo a repetir apenas os conteúdos sistemáticos pré-estabelecidos. O leitor da aula, no caso o aluno, a partir de suas experiências, relê os saberes históricos escolares criando um discurso em que seus posicionamentos passam a ser perceptíveis ao longo do texto. Em sintonia com o pensamento de Certeau (2014) pode-se, até mesmo, falar que, ao observarem e fazerem as leituras das aulas, os discentes não têm como continuarem do mesmo modo. Eles são modificados pelo que leram e acabam produzindo relatos que fabricam narrativas, em que outras vozes, antes silenciadas, agora podem ser ouvidas. 
Nos próximos excertos, percebe-se também que os relatos foram tecidos a partir do desenvolvimento de inferências. Nesse caso específico, a história escolar acaba servindo como base para as interpretações dos alunos acerca de outros acontecimentos, estejam esses associados a diferentes temporalidades. Sendo assim, outros significados podem ser tecidos para o próprio passado, para o presente e para hipotetizar o futuro. Nos fragmentos de Dadá e Extremista Radical os conteúdos foram mobilizados para construir entendimentos sobre as realidades atuais. Por caminhos diferentes, em Lane e Canlabaxúria predomina uma vinculação entre acontecimentos na mesma temporalidade, o passado. E Bruno ensarilha as três dimensões - passado, presente e futuro - produzindo, a partir dos saberes estudados, uma perspectiva de acontecimentos futuros:

Em seguida o primeiro grupo foi apresentar, eles abordaram o tema música de protesto onde falaram que as músicas que de certo modo reivindicava o nosso direito. Percebi que cantores famosos hoje como Chico Buarque, Caetano Veloso e Rita Lee já tiveram muitos problemas com as autoridades, por causa de letras de músicas, eles foram muito perseguidos pelo regime militar, inclusive, Chico Buarque a ser 'expulso' do Brasil por causa de suas músicas (Dadá, 2017).

Uma das consequências, a mutilação, foi mostrada uma charge, onde os Europeus buscaram dividir a África, sem consentimento dos demais africanos. Foi mostrado um gráfico da África antes e depois da chegada dos Europeus, o que a África é hoje então é resultado do Imperialismo Europeu (Extremista Radical, 2017b).

[...] Podemos dizer que o nazismo começou em 1919, e o lugar que foi disseminado foi na Alemanha num partido de extrema direita, assim como o fascismo o nazismo era antiliberal, você era quase obrigado a fazer tudo que eles quisessem mal tinha domínio próprio, teve um sentimento de vingança que originaria logo mais a segunda guerra mundial [...] (Lane, 2017).

O assunto Ditadura Civil Militar, período conhecido como anos de chumbo, onde a democracia acabou e se fez um regime autoritário. Liberdade não havia e censurar a todo e qualquer veículos de informações eram constantes o direito de voto também acabou. O bipartidarismo foi uma forma mais fácil de controlar a oposição. Todos os presidentes deste período foram militares, os Atos Institucionais que nada mais era ordem do presidente, e foi conhecido como $\mathrm{Al}$ 1 ...Al4, até estes atos foram conhecidos como um tanto quanto moderados a partir do Al5 as censuras passou a afetar muito diretamente a vida civil, pessoas eram presas, torturadas e mortas, muitas destas pessoas foram dadas como desaparecidas, e até hoje não se sabe o seu paradeiro (Canlabaxúria, 2017).

Esse governo durou apenas sete meses. Para mim, foi um governo péssimo, tipo o atual. Logo de início ele distanciou-se dos interesses dos Estados Unidos. Achando pouco, o mesmo congelou salários dos trabalhadores, porém, não teve apenas coisas ruins, teve uma boa, foi a seguinte: Jânio Quadros renunciou a presidência da república. Isso foi a única coisa boa. [...] E podemos ver claramente que de o governo atual continuar como está fazendo o que está fazendo, falando o que está falando "NÃO RENUNCIAREI", vamos acabar voltando a ter a renúncia como no governo de Jânio Quadros (Bruno, 2017b).

Ao realizarem esse processo nos reflexórios, os alunos mostram o quanto os saberes históricos escolares contribuem para a fabricação de sentidos para orientar e tornar mais concreto o cotidiano. Assim, o desenvolvimento do 
pensamento histórico acaba se sobressaindo por meio de um papel existencial, isto é, em que os raciocínios em torno das diversas temporalidades vão atribuindo sentidos e significados possíveis a própria pessoa, sujeito da reflexão; e aos acontecimentos das sociedades na atualidade e em outros momentos no tempo. Rusen $(2010 ; 2011)$ afirma que a aprendizagem histórica se distingue por ser um processo de elaboração de sentido sobre a experiência do tempo, cujas origens se dão em carências de orientação da vida prática.

Já os escritos de Extremista Radical e Índia foram construídos a partir de comparações entre momentos distintos da história política do Brasil. Vê-se que, no primeiro excerto, o processo comparativo foi fundamentado nas mudanças entre os governos Fernando Henrique Cardoso e Lula. O mecanismo para tornar esse processo evidente é o destaque aos aspectos vistos como negativos do período FHC, em contrapartida dos positivos de Lula. Na segunda citação, apresentou-se o entendimento de que existem continuidades entre os períodos políticos recentes da história brasileira. E essa ligação se deu no âmbito do desenvolvimento econômico do país:

[...] o primeiro grupo falou sobre o primeiro tópico do Governo FHC, que foi criado uma série de medidas para que o povo consumisse menos, alguns estados desligavam tudo até tal hora, foi um período bastante difícil, a falta de água nas hidrelétricas foi a maior causa disso. O governo Lula começou a investir em energia eólica, já para evitar possíveis acontecimentos de 'Apagão'. Foi falado também de energia termelétrica, que custava muito caro. O salário no governo FHC era de 64 reais, comprava-se apenas uma cesta básica, já no de Lula o salário mínimo era de 300 reais e comprava-se quase 5 cestas básicas. Também Lula fez o programa 'Luz para todos' que beneficiou mais de 10 milhões brasileiros, foram feitas 10 universidades contra nenhuma de FHC. $\mathrm{Na}$ era Lula mais de 23 milhões de pessoas saíram da pobreza, num vídeo que nos foi passado percebi a maioria de benefícios do governo Lula contra minoria de FHC, FHC enfatizava a economia já Lula fazia ênfase a sociedade, dois contextos extremamente diferentes (Extremista Radical, 2017a).

Um dos pontos dessa história que mais me chamou a atenção foi os desafios da era FHC. A era FHC foi caracterizada principalmente pela tentativa de estabilização da economia brasileira, condições importantes para o crescimento visto na era Lula. Ao Contrário do que muita gente pensa, a vitória contra a inflação não ocorreu apenas com o plano Real, no Governo Itamar (Índia, 2017).

Os relatos dessas aulas mostram o quanto a estratégia de comparação possibilita a construção e apropriação de um raciocínio que leva em consideração as noções de tempo histórico. Dessa maneira, o trabalho com as temporalidades não significa que o tempo seja o conteúdo sistemático esmiuçado em sala, mas torna-se um pressuposto metodológico central para a compreensão e raciocínio histórico (Schmidt; Cainelli, 2009). O Extremista Radical fundamentou as mudanças por meio dos contrapontos de níveis de duração ligados às conjunturas. $O$ econômico se associa ao governo Fernando Henrique Cardoso e o social se refere ao de Lula. E Índia mobilizou as conjunturas econômicas no intuito de apoiar a sua percepção sobre os elementos de continuidade.

A partir disso, pode-se perceber ainda que há entre os alunos distintas maneiras de se temporalizar os fatos históricos. Mesmo lidando com conteúdos iguais, Extremista Radical e Índia usam os níveis de duração para conceber sentidos diversos aos processos da história recente do país, revelando, com isso, 
até mesmo graus de importância. Para o primeiro, as questões sociais foram compreendidas como mais importantes. Essa visão marca sua narrativa, quando ele percebe justamente o governo de Lula como positivo por enfatizar a dimensão social com mais afinco do que o de FHC. Para a segunda aluna, o aspecto econômico tornou-se elemento fundamental, pois acaba servindo de vínculo entre o período de Itamar Franco e os momentos políticos posteriores. Chartier (2010) afirma que esses modos diferentes de temporalizar se referem às condições econômicas e sociais, abrindo possibilidades para que as múltiplas temporalidades não sejam percebidas apenas como envoltórios objetivos dos fatos sociais. Elas demonstram, então, serem produtos de fabricações sociais que expressam os posicionamentos, os anseios e utopias dos indivíduos e de seu grupo social.

Outro aspecto a ser destacado, refere-se ao fato de que as relações temporais fabricadas pelos alunos passam por processos que vão se complexificando. Nesse sentido, elas não são compreendidas como uniformes e nem invariadas. Estas podem ocorrer mediante ligações mais simples, nas quais elementos ora de semelhança e ora de diferenças são apresentados entre os acontecimentos do passado e do presente sem terem a preocupação em desenvolver a argumentação em torno deles. Isso ver-se-á no excerto de Vini, quando ele aponta semelhanças entre os arranjos da Primeira República e os do Brasil atual e, também, quando cita diferenças acerca das questões sociais e econômicas desses dois momentos. $E$ algo parecido encontra-se ainda nas ideias de Flor, ao distinguir a situação das mulheres e trabalhadores no início do século XX e na contemporaneidade:

A república Velha (1ำ república), se iniciou por meio de alianças, entre elite e as forças armadas. Hoje vivemos algo parecido, partidos se juntam para conseguir o poder político, que acontece frequentemente nos municípios e capitais.

$\mathrm{Na}$ economia, podemos dizer que evoluímos, mas podemos melhorar, com a capacitação das pessoas, o número de analfabetismo diminuiu, fazendo com que, as pessoas não fiquem tão dependentes de favores oferecidos e buscar meios de se manter, movimentando a economia do país.

$\mathrm{Na}$ questão social, podemos dizer que a maioria das pessoas daquela sociedade, não tinha como a população questionar os que estavam a frente, hoje temos um maior número de pessoas graduadas e que buscam não aceitar tudo, sem poder opinar (Vini, 2017).

Aprendemos que a constituição republicana estabeleceu do estado três poderes legislativo, executivo e judiciário; o país deixou de ter uma religião oficial e que a nova estabeleceu também o voto universal masculino só podia votar maiores de 21 anos e alfabetizados e as mulheres continuaram excluídas para votar, diferentemente do nosso tempo que as mulheres, analfabetos e maiores de 16 anos podem votar (Flor, 2017a).

[...] a maioria dos trabalhadores urbanos encontrava-se empregada no setor de serviços, como balconistas, empregada doméstica, motoristas de bondes. Nas fábricas, fossem elas grandes ou pequenas, no setor de serviços e nas atividades extrativas e agropecuárias, não existia legislação trabalhista, como conhecemos hoje, não havia descanso semanal remunerado, férias ou aposentadoria diferentemente de hoje que temos tudo isso, férias a cada 30 dias ao ano, folga semanal e aposentadoria (Flor, 2017b). 
Os tipos de relações não se limitam aos apresentados acima. Existem tentativas de estabelecer as conexões temporais e de desenvolver argumentos, cuja função é de elucidar e tornar mais palpável a amarração entre os acontecimentos por meio de dados concretos. Assim o fez Zerodois ao descrever as similitudes entre os problemas urbanos das cidades brasileiras do começo do século XX e atualmente:

\begin{abstract}
Referente a urbanização nas cidades, que não tinha o sistema de esgotos, nem ruas com calçamento, muito menos luz elétrica, muitas cidades se encontravam em mal condições, com isso surgiu várias doenças. $E$ com isso o governo realizou a campanha da vacina, sendo que não foi aceita que se tornou a revolta da vacina, que deixou cerca de 23 mortos e cerca de 900 feridas. Desde já, muitas coisas mudaram, mas ainda permanecem algumas no início do século $X X, 48$ por cento das cidades, brasileiras não são saneadas. $E$ isso trouxe novamente a doença da febre amarela ao Brasil (Zerodois, 2017).
\end{abstract}

Há um estágio em que os nexos tanto de diferença, quanto de semelhanças são acompanhados pela tentativa de enquadrar, nesse jogo de temporalidades, a exposição de argumentos vinculados aos pontos de vista, às impressões, às expectativas e, até mesmo, aos desejos dos discentes sobre aquelas experiências vivenciadas. Bruno, após assemelhar e diferenciar aspectos políticos, econômicos e sociais sobre a Primeira República e o cenário contemporâneo do país, conclui que o Brasil teve avanços com relação à outrora, mas que não pode se limitar a isso:

No tempo da República Velha quase não tinha autonomia para nada e também dependiam muito de exportações. E em relação às alianças, com Temer na presidência, digamos que nós voltamos a esse tempo. Ele conseguiu a presidência por meio de alianças que era o que se fazia naquele tempo, só que na república velha era algo exposto para todos verem, e sendo a maioria analfabeta não tinham como questionar. Hoje, as trocas são proibidas, mas de forma indireta isso é realizado.

Se Formos comparar a economia, tudo mudou. O tempo da república velha foi um tempo de instabilidade econômica, mas, graças a Deus, nossa economia é um pouco autônoma se for comparada a antiga república. Na questão social, foi o que mais mudou! As pessoas são alfabetizadas e estimuladas a pensar. Com o estímulo a educação, a pobreza diminuiu um pouco, sem deixar de lembrar que foram criados programas de benefícios sociais para diminuir a pobreza no país. Na questão política, hoje somos uma democracia mais clara, temos nossos direitos, liberdade de expressão, direito de escolher em quem votar e temos muitas leis a nosso favor. Coisa que não tinha antes. Se formos fazer uma comparação direta, vamos chegar à conclusão que evoluímos bastante $\mathrm{e}$ que não podemos parar onde estamos (Bruno, 2017a).

De acordo com Elias (1998), o processo de complexificação na construção das associações temporais faz parte da capacidade dos seres humanos de sintetizar em uma mesma sequência os fatos vindos antes e depois, colocando-os em conjunto. Na sua percepção, ao usar-se esse mecanismo os indivíduos tornam presente os acontecimentos ausentes e acabam fazendo ligações destes com fatos experienciados no presente. Os alunos, ao fazerem o exercício de sistematizarem e exporem essas dimensões temporais, apropriam-se da aprendizagem que os 
distanciam de uma compreensão reducionista e presentista da realidade social. Assim, passam a utilizar, cada vez mais, dos jogos de temporalidade como meios de orientação para produção de entendimentos críticos e reflexivos sobre si e sobre a sociedade.

Contudo, desenvolver essa capacidade de associações temporais não surge de modo aleatório ou ocasional e, sim, passa por encadeamentos de aprendizagens, entrelaçadas às experiências individuais e sociais. Ainda conforme Norbert Elias, "É nessa capacidade de aprender com experiências transmitidas de uma geração para outra que repousam o aprimoramento e a ampliação progressivos dos meios humanos de orientação, no correr dos séculos." (1998, p. 33) Daí, a importância de a história escolar protagonizar táticas - como a dos reflexórios - no cotidiano da disciplina, em que os alunos tentem expressar os acontecimentos em uma perspectiva temporal, fabricando suas explicações sobre as relações entre passado e presente, mas associadas à experiência de ter conhecido a história de sua e de outras sociedades.

Por conseguinte, no itinerário de interpretação das fontes, pretendeu-se enfatizar uma construção do discurso menos estanque do que aquelas formadas por categorias rígidas. Mais uma escrita, cuja análise revela-se nos movimentos e nos deslocamentos. Assim como o viajante que ao longo do percurso seleciona, debruça o olhar, reflete e constrói ideias acerca de determinadas paisagens, aqui dir-se-ia que estas são os posicionamentos políticos, as inferências, as comparações e a orientação da vida. Os conteúdos que tais paisagens permearam foram diversas, muitas vezes, até antitéticos uns em relação aos outros. Em comum, possuem a tentativa de construir enunciados acerca dos saberes históricos praticados em sala de aula, os quais levam a marca de fabricação dos próprios sujeitos alunos. Construções, cujos sentidos e significados são oriundos das reflexões deles sobre suas vivências no cenário de sala de aula e escolar e das experiências sociais mais amplas, das quais fazem parte.

\section{Conclusões}

Para finalizar esse trabalho, retomar-se-á o objetivo inicial com as seguintes questões: os reflexórios contribuíram para refletir no/sobre processo de aprendizagens nas aulas? Especialmente, contribuíram para ressignificá-los? Em primeiro lugar, pode-se compreender que os discentes, ao tornarem sistemáticos e processuais os atos de observação e reflexão para fabricação dos reflexórios, construíram narrativas com identidades próprias. Singulares, visto que eram pautadas pelas contribuições do saber histórico escolar, mas também porque foram deixando, cada vez mais, transparecer as vozes dos sujeitos-alunos, cujas contribuições revelaram-se, por meio de suas próprias interpretações, envolvidas pelos significados, posicionamentos, angústias, dúvidas e raciocínios diversos que dão às realidades sociais. Dessa forma, dentro dos textos dos reflexórios acabaram se encontrando teias de outros textos, isto é, a reflexão, leitura e escrita feitas pelos discentes acerca das aulas são marcadas por suas experiências e aprendizagens sociais mais amplas, as quais contribuem para que eles possam ressignificar, a partir de novos pontos de vistas, o saber histórico praticado em sala de aula.

Essas contribuições podem perpassar a vida dos discentes à medida em que eles tomam consciência de que os saberes por eles fabricados acabam sendo meios para orientação de suas atitudes e tomadas de decisões em meios às 
complexas situações postas pela sociedade. Como puderam verificar, ao longo da análise das fontes, os posicionamentos políticos, os mecanismos de comparação e as inferências foram produzidas a partir de conhecimentos, os quais consideravam as dimensões temporais, concedendo assim aos alunos uma capacidade de raciocínio mais abrangente, crítico e autônomo com relação a si mesmo e às questões sociais que os envolviam.

Além do mais, na dimensão específica da avaliação na disciplina de História é perceptível que o uso dos reflexórios possibilitou o distanciamento de uma prática de ensino conteudista em que o conteúdo conceitual é aplicado tendo como objetivo central certificar-se no final do processo se houve uma apropriação pelos alunos. Não existindo aí nenhuma preocupação no desenvolvimento de outras aprendizagens pelo discente. Por outro lado, tal utilização propiciou a aproximação de práticas avaliativas que atentavam para além do desenvolvimento dos conteúdos conceituais, como a capacidade de ressignificá-los, de sistematizá-los por meio da escrita e da leitura. E relacionado a isso, os reflexórios tornaram-se instrumentos dinâmicos e móveis no decorrer do ano letivo, cujas paragens no percurso da viagem serviam para revisar e reabastecer de reflexões e de demais contribuições o próprio processo de ensinar e aprender em História.

\section{Referências}

Bia (2017, 14 jun.). Reflexório. Arez (Rio Grande do Norte).

Bittencourt, Circe (2004). Ensino de história: fundamentos e métodos. São Paulo: Cortez.

Bruno (2017a, 3 mar.). Reflexório. Arez (Rio Grande do Norte).

Bruno (2017b, 22 maio). Reflexório. Arez (Rio Grande do Norte).

Canlabaxúria (2017, 5 jun.). Reflexório. Arez (Rio Grande do Norte).

Certeau. Michel de Certeau (2014). A Invenção do cotidiano: artes de fazer. Tradução Ephraim Ferreira Alves. Petrópolis: Vozes.

Chartier, Roger (2010). A história ou a leitura do tempo. Tradução Cristina Antunes. Belo Horizonte: Autêntica.

Dadá (2017, 2 jul.). Reflexório. Arez (Rio Grande do Norte).

Dido (2017, 7 abr.). Reflexório. Arez (Rio Grande do Norte).

Elias, Norbert (1998). Sobre o tempo. Tradução Vera Ribeiro. Rio de Janeiro: Jorge Zahar.

Extremista Radical (2017a, 21 ago.). Reflexório. Arez (Rio Grande do Norte).

Extremista Radical (2017b, 4 set.). Reflexório. Arez (Rio Grande do Norte),

Flor (2017a, 10 mar.). Reflexório. Arez (Rio Grande do Norte).

Flor (2017b, 20 mar.). Reflexório. Arez (Rio Grande do Norte).

Garrido, Elsa (2001). Sala de aula: espaço de construção do conhecimento para o aluno e de pesquisa e desenvolvimento profissional para o professor. In: Castro, Amelia Domingues de; Carvalho, Anna Maria Pessoa de. (Org.) Ensinar a ensinar: 
didática para a escola fundamental e média. São Paulo: Cengage Learning. p. 125139.

Geertz, Clifford (2012). A Interpretação das culturas. Tradução Fanny Wrobel. Rio de Janeiro: LTC.

Geertz, Clifford (2014). O saber Local: novos ensaios em antropologia interpretativa. Tradução Vera Joscelyne. Petrópolis: Vozes.

Hoffmann, Jussara (2014). Avaliação mediadora: uma prática em construção da pré-escola à universidade. Porto Alegre: Mediação.

Índia (2017, 21 ago.). Reflexório. Arez (Rio Grande do Norte).

Lane (2017, 18 set.). Reflexório. Arez (Rio Grande do Norte).

Marcuschi, Luiz Antônio (2010). Gêneros textuais: definição e funcionalidade. In: Dionísio, Ângela Paiva; MACHADO, Anna Rachel; Bezerra, Maria Auxiliadora (Org.). Gêneros textuais e ensino. São Paulo: Parábola Editorial. p. 19-38.

Monteiro, Ana Maria (2007). Professores de história: Entre saberes e práticas. Rio de Janeiro: Mauad X.

Perissé, Paulo (2004). O educador aprendedor. São Paulo: Cortez.

Ricoeur, Paul (2018). Teoria da interpretação: o discurso e o excesso de significação. Tradução Artur Morão. Lisboa: Edições 70.

Ricoeur, Paul (2011). Escritos e conferências 2: hermenêutica. Tradução Lúcia Pereira de Souza. São Paulo: Edições Loyola.

Rusen, Jorn (2010). Razão histórica: Teoria da história: os fundamentos da ciência histórica. Tradução Estevão Rezende Martins. Brasília: Ed. UnB.

Rusen, Jorn (2011). Jorn Rusen e o ensino de história. Curitiba: Ed. UFPR.

Schmidt, Maria Auxiliadora; Cainelli, Marlene (2009). Ensinar história. São Paulo: Scipione.

Vini (2017, 3 mar.). Reflexório. Arez (Rio Grande do Norte).

Zerodois (2017, 20 mar.). Reflexório. Arez (Rio Grande do Norte). 